\title{
Success Factors for Federated Enterprise Architecture Model Management
}

\author{
Pouya Aleatrati Khosroshahi ${ }^{1}$, Stephan Aier $^{2}$, Matheus Hauder ${ }^{1}$, Sascha Roth ${ }^{1}$, \\ Florian Matthes ${ }^{1}$, Robert Winter ${ }^{2}$ \\ ${ }^{1}$ Technische Universität München, Chair for Informatics 19 (sebis), \\ Boltzmannstrasse 3, 85748 Garching bei München, Germany \\ \{p.aleatrati, roth, matheus.hauder, matthes\}@tum.de \\ ${ }^{2}$ University of St. Gallen, Institute for Information Management, \\ Mueller-Friedberg-Strasse 8, 9000 St. Gallen, Switzerland \\ \{stephan.aier, robert.winter\}@unisg.ch
}

\begin{abstract}
Recent approaches for managing Enterprise Architecture (EA) models provide technical systems to procure information from existing repositories within the application landscape of an organization. Beyond technical solutions, social factors are of utmost importance to implement a successful EA initiative. Institutional theory has for example been employed to understand crucial factors for realizing EA management (EAM) benefits through architectural thinking. Yet, it remains unclear how these social factors influence a federated approach for EA model management. Based on a socio-technical systems perspective, we investigate success factors for Federated EA Model Management (FEAMM) by conducting qualitative interviews with industry experts. Our findings suggest that success factors for FEAMM are related to the model sources, modeling instruments, and model integration aspects from a technical perspective as well as to organizational grounding, governance, enforcement, efficiency, goal alignment, and trust from a social perspective.
\end{abstract}

Keywords: Federated Enterprise Architecture Model Management, Institutionalization, Socio-technical System

\section{Motivation}

Increasing complexity of business transactions as well as an accelerated rate of change due to globalization and fierce competition demand for continuous alignment of organizational structures with strategic goals. Enterprise Architecture and the corresponding management function are discussed as an effective means to improve alignment of business with its supporting information systems (IS) and technology (IT) [5], [37]. Empirical data confirm the potential of this discipline to achieve and maintain IS/IT efficiency and effectiveness while contributing to the business value of an organization [9], [20]. Among others, one of the essential requirements to realize these benefits is the creation of transparency about the current and future state of the organization's architecture among relevant stakeholders.

EA models facilitate this transparency and provide the foundation for measurability, consistency, as well as a shared language and understanding among diverse stakeholders [1], [2], 
[10], [21], [33], [34]. EA modeling is a cross-cutting effort that documents the organization's structure, e.g., IS, business processes, infrastructure components as well as their relationships. Particularly in medium and large organizations, EA models grow huge. Creating and maintaining these models can only be achieved by division of labor and the reuse of available data. Several already existing models might be maintained for specialized purposes in the organization, e.g., configuration management databases, license management and project portfolio management tools [17]. FEAMM is an approach to integrate existing special purpose models by transforming relevant horizontal (enterprise-wide), vertical (business-to-IT), and time dimensions (planning) of the information [18]. In FEAMM formerly independent models providing partial perspectives of an organization are linked to an EA repository through meta-model integration.

Successful management of the EA relies on solid and up to date information provided by these federated models. Ensuring topicality and consistency of the EA model requires maintenance processes that are either run periodically or triggered by specific events, e.g., certain project milestones [4], [18]. These maintenance processes require the active involvement of EA stakeholders and data owners that provide the information from federated models and revise inconsistencies during the integration with the EA meta-model [18]. While research recently promotes technical systems that attempt to support stakeholders of FEAMM with the automated provisioning of aggregated information from existing specialized models [14], [31], the enterprise-wide stakeholder engagement for sharing local data and contributing to an enterprise-wide EA model remains a major challenge. The active engagement of stakeholders during the creation and maintenance processes requires an institutionalization of EA in the organization. Next to strict governance mechanisms that enforce the involvement of stakeholders in maintenance processes, successful FEAMM relies on the organizational grounding, social legitimacy, efficiency, and trust of EA in the organization [38]. Governance aspects that are important for the successful establishment of FEAMM need to consider these social as well as technical aspects. Against this background we formulate the following research question:

What are social and technological success factors for Federated EA Model Management?

Our findings summarize novel and integrated success factors that are crucial for the establishment of a successful FEAMM in order to maintain a solid and up to date model that can serve as a foundation for successful EA management. While existing research mainly investigates technology to automate the provision of EA information from existing specialized models in the organization [14] [29], this paper considers the socio-technical perspective in which FEAMM is embedded.

\section{Related Work}

In this section we discuss related work regarding the general idea of FEAMM, methods and techniques used, and the social aspects of anchoring the general idea of EA and FEAMM in an organization.

Roth coined the term FEAMM [28] describing a phenomenon often observed in industry during the procurement of information for an EA model. FEAMM is an organizational setting in which a central EA management function integrates models of highly specialized, semi-autonomous IT management functions referred to as communities. Each community performs tasks which follow processes defined either explicitly or implicitly. These processes are supported by technology. In [28] we report that each modeling community can be considered a separate linguistic community. That means each community describes real-world objects with their own terminology. Although the modeling communities may refer to the same real-world objects, they use different names and attributes to describe them. Multiple modeling communities perform their tasks employing highly specialized repositories incorporating best-practice knowledge. In [22], Goodhue and Thompson observe a phenomenon and coined the phrase 'task technology 
fit'. The authors highlight that individual performance rises if a good fit prevails between employed technologies and the task. Hence we conclude that the repositories employed by the different communities are intended to fit best for the tasks at hand for this particular community.

The concept of FEAMM embraces technical details, relevant information sources, data quality aspects, documentation processes, and respective challenges that arise when procuring information from existing repositories. These aspects have been investigated by different research groups, e.g. Farwick et al. [15], Buschle et al. [11], or Roth et al. [31]. Further, requirements [16], governance and processes [15], [18], case studies [17], and issues [23] are pointed out by these research groups. Roth et al. note that the teams of modeling communities are aware that the information they maintain may contribute to the overall performance of an organization and proposes an approach for FEAMM assuming that the modeling communities are willing to share information, which, however, might not always be the case. Important for a successful FEAMM are governance aspects such as role allocations [28], [31] and a clear definition of responsibilities [28] and escalation paths in case a conflict between two repositories describing the same realworld object occurs [30].

Closely related to our work are the findings reported by Lange et al. [25]. The researchers report on success factors found in literature and explain a theoretical model that aims at the realization of EA benefits. Schmidt and Buxmann perform a field survey on outcomes and critical success factors for EA management [13]. While both, the research group around Lange et al. and Schmidt and Buchmann, investigate EA management function in general, we focus on success factors with respect to FEAMM.

As of today, no research group investigated how to get stakeholders to share EA information. In contrast, Hauder et al. [23] report that sharing information without clear benefits is often an issue of EA management initiatives. We argue that sharing EA information among communities requires prior institutionalization of EA management. Despite the maturity of EA methods and techniques, it remains challenging to effectively anchor, i.e., institutionalize EA in an organization [33], [38]. Ross and Quaadgras [27] found that "business value accrues through management practices that propagate architectural thinking throughout the enterprise". What is needed is an architectural thinking as "the way of thinking and acting throughout an organization, i.e. not restricted to architects and system developers" [40].

Weiss et al. [38] therefore propose an institutional theory perspective on EA research. They employ institutional theory in order to understand how organizations and individuals respond to pressures - in our case the need to share and integrate their local EA models. They find that the stakeholders' response towards EA is influenced by the social legitimacy and efficiency stakeholder's gain, by the organizational grounding of EA, and by the trust stakeholders have in the EA unit. They also find that governance mechanisms, stakeholders' goal alignment with general EA goals, and enforcement of EA foster EA consistency and adoption. Wieland et al. first propose to deal with model conflicts and merging with human intervention [39]. However, their approach addresses software models and thus cannot be directly applied to EA models.

While methods and models for an automation of FEAMM are elaborated at a rather technical level by research outlined above, in line with Roth [28], we identify a research concerning governance aspects, role integration in organizational processes, and the complex social interactions across diverse communities in an organization.

\section{$3 \quad$ Research Methodology}

\subsection{Research Model}

In the paper at hand we analyze our empirical data through the lens of socio-technical systems theory and its four perspectives of task, technology, people, and structure (cf. Fig. 1) [7]. Socio- 
technical systems theory conceptualizes an organization as a system with two interrelated subsystems, the technical system and the social system.

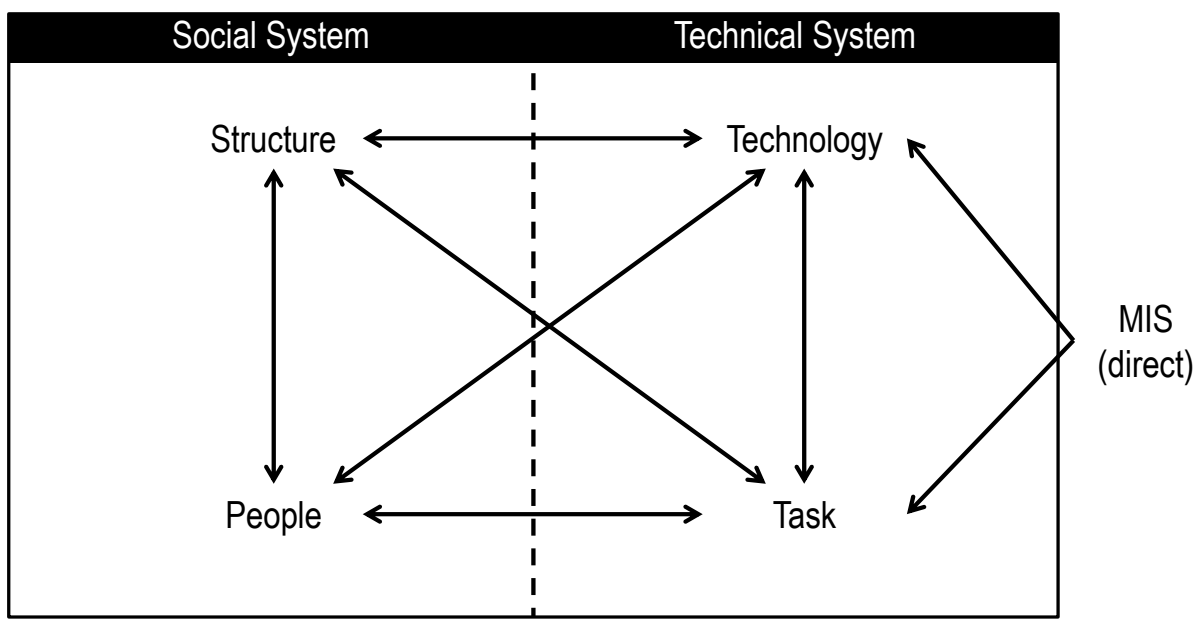

Fig. 1. Interacting classes and their relationships in socio-technical systems theory [7]

The technical system is concerned with the processes, tasks, and technology needed to transform inputs such as materials or information to outputs such as products or services. The social system is concerned with the relationships among people and the attributes of these people such as attitudes, skills, and values. The outputs of the entire system are a result of the joint interaction between these two systems [8]. System designs that ignore one of these dimensions are expected to perform worse or even fail to achieve their goals compared to designs that cater for all four perspectives.

\subsection{Research Approach}

FEAMM is rarely discussed in academia and practice. Thus, we conducted 11 interviews with EA experts across various industries and various job positions to get different views on how EA experts deal with FEAMM practices and which governance structures support these. Table 1 gives an overview of the interview participants.

Table 1. Overview of Interview Participants

\begin{tabular}{|l|l|l|l|}
\hline$\#$ & Position & Industry & No. of Employees \\
\hline 1 & Enterprise Architect & Insurance & $\sim 5.000$ \\
\hline 2 & Enterprise Architect & Manufacturer & $\sim 50.000$ \\
\hline 3 & IT Architect & Manufacturer & $>100.000$ \\
\hline 4 & Enterprise Architect & Insurance & $\sim 10.000$ \\
\hline 5 & Senior Manager & Consulting & $>100.000$ \\
\hline 6 & Enterprise Architect & Public Sector & Ns. \\
\hline 7 & Senior Consultant & Consulting & $<1.000$ \\
\hline 8 & Executive Assistant & Insurance & $\sim 50.000$ \\
\hline 9 & IT Architect & Insurance & $\sim 10.000$ \\
\hline
\end{tabular}




\begin{tabular}{|l|l|l|l|}
\hline 10 & Enterprise Architect & Insurance & $\sim 100.000$ \\
\hline 11 & Professor & Research & $<1.000$ \\
\hline
\end{tabular}

To ensure anonymity of participants, an aggregated view on the interview data is provided [35]. We employ semi-structured interviews with open questions to create the opportunity for EA experts to discuss a broad range of aspects of FEAMM [24]. We provided the interviewees with an interview guideline illustrating the research topic. Although, the interviews followed a semi-structured style, we pay attention to include questions referring to preferred role allocations, governance principles and used methods in case of establishing a FEAMM within the corresponding organization. The interview duration ranges from 23 to $120 \mathrm{~min}$ (68 min in average). All interviews were recorded, transcribed, and sent back to the participants to ensure the correctness of the transcripts [19]. The experts interviews were analyzed according to a concept matrix based method by Webster \& Watson [36].

\section{$4 \quad$ Empirical Findings}

Our empirical data cover organizational aspects and technical aspects of FEAMM. The organizational aspects provide information about preferable governance structures, such as role allocation and non-technical prerequisites. Moreover, we analyzed incentives that might increase the participation in FEAMM activities, for instance use cases that benefit from FEAMM. Technical aspects include information about the direction of data flow between communities, the EA model and the application of ontologies when maintaining FEAMM. Moreover, the empirical data provide information about the current status of EAM within the respective organizations and reflect specific use cases that might benefit from establishing FEAMM.

\subsection{Use Cases of Federated EA Model Management}

Most of the interviewed EA experts stated that EAM is perceived as a significant asset within their respective organization. EAM supports running business activities by identifying relevant information sources, transforming the EA landscapes to provide appropriate data flows for business requirements and supports mandatory tasks, such as the implementation of regulatory requirements [6]. Most of the interviewees stated that EAM is driven by IT departments and rather by than business departments. The problem is that business departments neither observe any benefit from EAM nor believe that their running business would change. Furthermore, the interviewees face the problem of missing management support and a low priority of EAM. Daily business activities and mandatory issues such as regulatory requirements receive higher priorities. Thus, we asked the EA experts for use cases in which a federated EA model would realize a benefit for the majority of the stakeholders within the respective organization. We received the following use cases from the conducted expert interviews:

IT Controlling: These days, there are several possibilities to allocate overhead to specific products within a company, such as the marginal planned cost accounting approach. Groups operate across various countries and run thousands of IT applications and databases. Moreover, current IT landscapes of today's organizations face frequent changes with respect to daily migrations and software implementation projects. As a consequence, companies have an issue to both comprehensively and correctly capture the status quo of IT landscapes. 7 out of 11 EA experts stated that a federated EA model can be a useful information source for IT controlling purposes: All EA related information are stored within a federated EA model and provide the required information to identify used IT components within an organization and allocate them to products or specific communities. 
Trends and forecasting: Depending on the defined or available attributes for the considered entities within a federated EA model, the single instances might provide information regarding their storage, the supported business processes or the current status of issues within the specific instance (such as failed interface transfers between two databases). 5 out of 11 EA experts stated that this information would support forecasting activities with regard to the current EA landscape.

Planning and controlling the EA landscape: Within large organizations, IT landscapes have developed in a heterogeneous way and contain various IS components. One EA expert mentioned that his organization runs over 150 information systems. The respective company is facing the challenge of missing transparency and non-existing documentation of the introduced ISs. A federated EA model helps to cope with these barriers by providing a clear overview of the current IT landscape and thus supports the strategic planning of the EA. 4 out of 11 interviewed EA experts confirmed this use case. Single EA experts mentioned further use cases that do not fit to all organizations and depend on characteristics of specific markets.

Regulatory requirements: Financial service providers in particular face the problem of upcoming Solvency II or IFRS 4 Phase 2. These regulatory requirements ask among other for the used ISs with regard to risk management purposes. A federated EA model can provide required information.

Chief information officer (CIO) reporting: IT departments are encouraged to report the current status - such as used IS components - to the CIO of the organization. A federated EA model provides the information to facilitate this reporting.

Transformation projects: Companies put much effort in solving the obstacle of heterogeneous IT landscapes by conducting IS harmonization and migration projects, i.e., transformations. A clear overview of the EA landscape and the implemented data flows between the ISs are the foundation of transformation projects. A holistic EA model provides this information.

\subsection{Lean Role Allocation Approach}

During the expert interviews, it turned out that industry experts prefer a pragmatic approach with fewer roles. The involvement of too many roles lead to bureaucratization of the maintenance process and influence the efficiency of it. Moreover, all interviewed EA experts prefer to involve the Domain Architect within the maintenance activities of the EA model. A Domain Architect acts as a specialist for a specific business or technology domain such as IBM DB2. The Enterprise Architect has an overarching role within the maintenance process and is involved in the majority of the conducted activities. EA experts prefer to limit the involvement of different roles to a minimum.

\subsection{Incentives to Participate in FEAMM}

The participation of business stakeholder and all communities is mandatory to keep a federated EA model up to date. We asked the EA experts, how to convince business stakeholder to participate in FEAMM activities. Two different strategies to convince the communities to participate in FEAMM have been identified:

Social methods: One mentioned possibility is to provide incentives that convince organizational members on a social level to participate in FEAMM activities. Incentives might be the agreement on objectives or an extra bonus. 4 out of 11 EA experts tries to convince Data Owners for providing necessary EA information by using social methods.

Governance pressure: A dedicated supervisory makes use of governance procedures to ensure that single communities provide the information on a granular level. This method requires the 
support of upper management, strict EA principles and the definition of escalation paths. 5 out of 11 EA experts make use of governance pressure to get EA information by single communities.

\subsection{Terminology Alignment is a Necessity}

Conflicts between instances lead to model inconsistency issues and have to be solved within the staging area. Conrad [12] provides a categorization of data conflicts - such as semantic conflicts or structural conflicts - in terms of federated databases that might also occur in a federated EA model. In order to guard against the majority of conflicts, the EA experts mentioned that an aligned EA terminology is a mandatory prerequisite before starting to design, develop, and maintain a federated EA model. The alignment process requires the participation of all modeling communities, Enterprise Architects, and of an EA board or a comparable supervisory. The alignment process can be divided in three phases:

General setup activities: In this starting phase, the EA board and the Enterprise Architects set the scope of the alignment - such as the considered entities - and define governance principles for the alignment process. Furthermore the process will be tested with one community in form of a pilot study to identify missing unnoticed circumstances and obstacles. The results of the pilot study will be evaluated and used for re-scoping the planned alignment process. The finalized governance structure and the alignment scope will be communicated to all communities

Iterative standardization: Enterprise Architects conduct workshops with the single communities to define the necessary terminology adjustment for the respective entity. The standardization process follows an iterative approach: An iteration is always comprised of one entity such as application or platform.

Final sign-off: The finalized EA terminology needs to be signed-off by the EA board.

The majority of the EA experts prefers a lean, pragmatic, and agile alignment process with less involvement of stakeholders. Moreover, EA experts asked for stronger business involvement and think that escalation paths to the EA board within all activities are mandatory to solve disputes between communities.

\subsection{Application of Ontologies}

Ontologies relate to semantic web technologies that can be used to integrate heterogeneous data sets into a formalized structure [32]. Referring to the conflict resolution process, ontologies support the identification of conflicts in an automated way.

It turned out that ontologies are not a preferred supporting option for the conflict resolution process of FEAMM. All interviewed EA experts disagreed to use ontologies within a FEAMM. Rather, it has only significance in the academics area of EA. These EA experts that were familiar with the concept mentioned that ontologies could be interesting in the future: The application of ontologies requires highly homogenous data sets and major efforts (referring to data standardization and customization of running ISs). Moreover, other issues, such as the implementation of regulatory requirements in the insurance sector, have a higher priority.

\subsection{Unidirectional vs. Bidirectional Data Flow}

Communities have to transfer the EA model information - either automatically or manually - to the centralized EA model. There is the possibility to transfer information from the EA model to the communities as well. We evaluated whether the experts prefer a unidirectional or a bidirectional data flow. 
- Machine-to-machine communication: The EA repository system can change or transfer data sets within the ISs of the single communities.

- Machine-to-person communication: The EA repository responsibility communicates information to the communities, but is not authorized to change or transfer data sets within the ISs of the communities.

The communication of EA model information to the community supports data standardization issues and provides useful means to communicate new governance standards to the communities. However, the communities have to ensure the full control about their productive data. EA experts mentioned that wrong data changes might impact the running business of the communities.

\section{Discussion}

We analyze the empirical data of the expert interviews using the socio-technical system theory framework to structure our research results (cf. Fig. 2). Key findings of the empirical analysis are placed in four areas of the socio-technical system: Structure, People, Technology, and Task. We allocate the key findings to institutional factors, partly provided by Weiss et al. [38] that influence FEAMM.

This view places the key findings of the empirical data on the four areas of the socio-technical system: Structure, People, Technology and Task. Moreover, we allocated the key findings to institutional factors, partly provided by Weiss et al. [38] that impact the management of a federated EA model.

Structure: Ross [26] states business stakeholders rarely participate in EAM activities because it lacks direct value for them. Our empirical findings show that the participation of all modeling communities is mandatory to ensure a comprehensive and correct federated EA model. For this purpose, FEAMM demands strict EAM principles, escalation paths, and governance pressure (cf. [28]). The definition and operation of these measures influence the Governance of FEAMM. Moreover, the current priority of EAM within an organization influences the Organizational Grounding of FEAMM.

People: EA experts mentioned they prefer a lean role allocation across all FEAMM activities and face the problem of missing documentations regarding their productive ISs and skills to alter the IS. These two factors influence the Efficiency gains through FEAMM. The definition of too many roles within FEAMM leads to bureaucracy and might impact the efficiency of FEAMM negatively. Moreover, missing documentations about the productive ISs lead to major efforts for transformation activities. EA experts also pointed out that the involvement of business stakeholder is mandatory for the efficient FEAMM. Use cases-such as the implementation of regulatory requirements - relate to business issues. Thus, a federated EA model should provide appropriate information. In line with Ahlemann et al. [3], EA experts also confirmed that incentives to participate in FEAMM activities are an essential factor. These factors attract further attention regarding Goal Alignment measures between FEAMM and business goals. Moreover, EA experts confirmed that the support of the upper management and the conviction of non-EAM stakeholder in the meaningfulness of FEAMM are mandatory. Organizations stakeholder have to trust the EAM function.

Technology: Hauder et al. [23] already highlighted that issues in data quality have a severe impact on EA documentation activities and hence on FEAMM. The interviewees confirmed this issue. As aforementioned, one EA expert pointed out the problem of missing scalability of source systems. These two factors can be aggregated as Model Source factors. Furthermore, the empirical data reveals opinions about ontologies, data flow directions, and further technology based factors that can be summarized in Modeling Instrument factors. 
Task: Considering FEAMM on a higher level, the overarching goal is to improve EAM Transparency within an organization. The increased transparency supports the operation of specific use cases, such as IT controlling. Model Integration embraces organizational roles and responsibilities for the configuration of a mapping between the information sources and the EA repository, which is part of the initial integration process (cf. [28]). This integration is the foundation for importing information to merge the different (partial) models into the EA model. During such a merge it is of utmost importance to resolve responsible roles for the conflict resolution subprocess.

Fig. 2. Success Factors of a Federated Enterprise Architecture Model Management

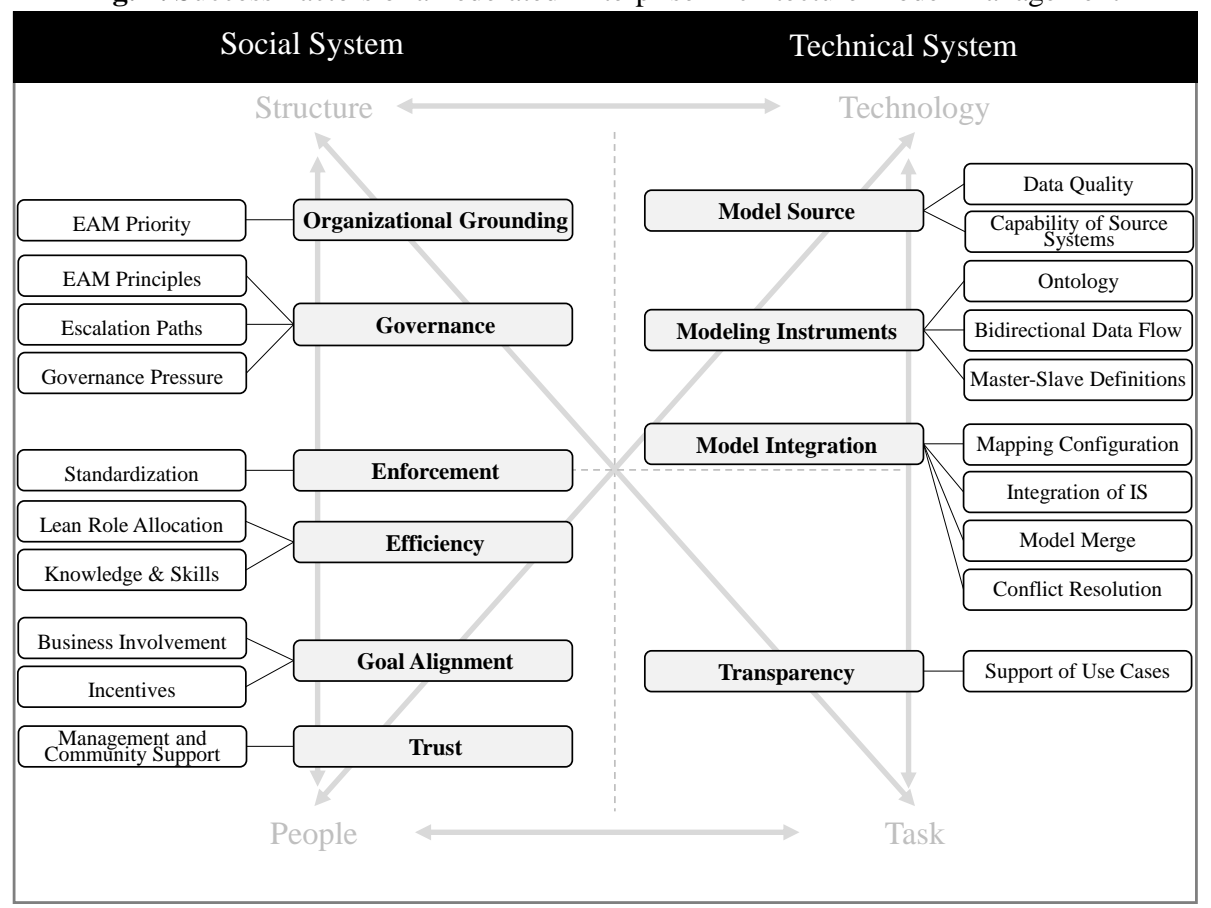

\section{Conclusion}

In this paper, we provide empirical insights on important success factors for FEAMM. We took a socio-technical systems perspective to present our results to illustrate factors that influence the implementation and maintenance of FEAMM.

The results show that today's organizations prefer a pragmatic FEAMM approach with strong business involvement and a lean role allocation. However, it turned out that the implementation of FEAMM meet various organizational challenges that need to be resolved previously such as the establishment of a standardized EA terminology. Moreover, technical requirements such as an adequate tool support need to be considered (cf. [28]).

Further research may provide quantitative evidence of these success factors and reveal other important factors for successful FEAMM initiatives. Moreover, the role of business stakeholders within FEAMM in terms of implementation and maintenance activities have to be evaluated. 


\section{References}

[1] Abraham, R. Enterprise Architecture Artifacts as Boundary Objects - A Framework of Properties. In European Conference on Information Systems (ECIS '13) (Utrecht, The Netherland, June 5-8, 2013).

[2] Abraham, R., Niemietz, H., de Kinderen, S., Aier, S.: Can boundary objects mitigate communication defects in enterprise transformation? Findings from expert interviews. In Proceedings of the $5^{\text {th }}$ International Workshop on Enterprise Modelling and Information Systems Architectures (EMISA '13) (St. Gallen, Switzerland, 2013)

[3] Ahlemann, F., Stettiner, E., Messerschmidt, M., Legner, C. Strategic enterprise architecture management: challenges, best practices, and future developments, Springer Verlag $\mathrm{GmbH}, 2012$.

[4] Aier, S., Buckl, S., Franke, U., Gleichauf, B., Johnson, P., Närman, P., Schweda, C., Ullberg, J. A Survival Analysis of Application Life Spans based on Enterprise Architecture. In Proceedings of the $3^{\text {th }}$ International Workshops (EMISA '09) (Ulm, Germany, September 09-11, 2009).

[5] Aier, S., Gleichauf, B., Winter, R. Understanding Enterprise Architecture Management Design - An Empirical Analysis. In Proceedings of the 10th International Conference on Wirtschaftsinformatik (WI '11) (Zurich, Switzerland, April 16-18 2011.

[6] Aleatrati Khosroshahi, P., Roth, S., Hauder, M. Impact of Solvency II on the Enterprise Architecture of Insurances: A Qualitative Study in Germany. In Multikonferenz Wirtschaftsinformatik (MKWI 2014) (Paderborn, Germany, February 26-28, 2014).

[7] Bostrom, R. P., Heinen, S. MIS Problems and Failures - A Socio-Technical Perspective. Part I - The Causes. MIS Quarterly, 1, 3 (1977), 17-32.

[8] Bostrom, R. P.. Heinen, S. MIS Problems and Failures - A Socio-Technical Perspective. Part II - The Application of the Socio-Technical Theory. MIS Quarterly, 1, 4 (1977), 1128.

[9] Boucharas, V., van Steenbergen, M., Jansen, S., Brinkkemper, S. The contribution of enterprise architecture to the achievement of organizational goals: Establishing the enterprise architecture benefits framework, Technical Report UU-CS-2010-014, Utrecht University, Utrecht, 2010

[10] Buckl, S., Matthes, F., Roth, S., Schulz, C., Schweda, C. M., A Conceptual Framework for Enterprise Architecture Design. In Workshop on Trends in Enterprise Architecture Research (TEAR '10) (Delft, The Netherlands November 15, 2010).

[11] Buschle, M. Holm, H. Sommestad, T. Ekstedt, M. Shahzad, K. A Tool for automatic Enterprise Architecture modeling. IS Olympics: Information Systems in a Diverse World, 107, (2012), 1-15.

[12] Conrad, S. Föderierte Datenbanksysteme - Konzepte der Datenintegration. Springer Verlag GmbH. Heidelberg, Germany, 1997.

[13] Schmidt, C., Buxmann, P. Outcomes and success factors of enterprise IT architecture management: empirical insight from the international financial services industry. European Journal of Information Systems, 20, 2 (2011), 168-185.

[14] Farwick, M., Schweda, C., Breu, R., Hanschke, I. A situational method for semi-automated Enterprise Architecture Documentation. In Software \& Systems Modeling (2014), 130.

[15] Farwick, M. Agreiter, B. Breu, R. Ryll, S. Voges, K. Hanschke, I. Automation processes for enterprise architecture management. In Enterprise Distributed Object Computing Conference Workshops (EDOCW '11) ( Helsinki, Finnland, August 29 - September 2, 2011)

[16] Farwick, M. Agreiter, B. Breu, R. Ryll, S. Voges, K. Hanschke, I. Requirements for Automated Enterprise Architecture Model Maintenance - A Requirements Analysis based on a Literature Review and an Exploratory Survey. In Proceedings of the 13th International 
Conference on Enterprise Information Systems (ICEIS '11) (Beijing, China, June 8-11, 2011).

[17] Farwick, M., Breu, R., Hauder, M., Roth, S., Matthes, F. Enterprise Architecture Documentation: Empirical Analysis of Information Sources for Automation. In 46th Hawaii International Conference on System Sciences (HICSS '13) (Maui, Hawaii, January 7-10, 2013).

[18] Fischer, R., Aier, S., Winter, R. A Federated Approach to Enterprise Architecture Model Maintenance. Enterprise Modelling and Information Systems Architectures, 2, 2 (2007), 14-22.

[19] Flick, U., Kardorff, E. von and I. Steinke. An Introduction to Qualitative Research. 4th Edition, Sage Publications, London, Thousand Oaks, California, New Delhi, Singapore, 2006.

[20] Foorthuis, R., van Steenbergen, M., Mushkudian, N., Brinkkemper, S., Bos, R. On course, but not there yet: Enterprise architecture conformance and benefits in systems development. In International Conference on Information Systems (ICIS '10) (Saint Louis, USA, December 12-15, 2010).

[21] Frank, U., Strecker, S., Fettke, P., Brocke, J., Becker, J., Sinz, E. The Research Field "Modeling Business Information (January 2014), 39-43.

[22] Goodhue, D. L., Thompson, R. L., Task-Technology Fit and Individual Performance. MIS Quarterly, 19, 2 (1995), 213-236.

[23] Hauder, M., Matthes, F., Roth, S. Challenges for Automated Enterprise Architecture Documentation. In Trends in Enterprise Architecture Research and Practice-Driven Research on Enterprise Transformation, 2012.

[24] Kvale, S. Doing interviews. Sage Publications, 2008.

[25] Lange, M., Mendling, J., Recker, J. A comprehensive EA benefit realization model - An exploratory study. In 45th Hawaii International Conference on System Sciences (HICCS '12) (Maui, Hawaii, January 4-10, 2012).

[26] Ross, J. W. Creating a Strategic IT Architecture Competency: Learning in Stages. April 2003.

[27] Ross, J., Quaadgras, A. Enterprise Architecture Is Not Just for Architects, Center for Information Systems Research, Sloan School of Management, Massachusetts Institute of Technology, Cambridge, USA, 2012.

[28] Roth, S. Federated Enterprise Architecture Model Management - Conceptual Foundations, Collaborative Integration, and Software Support. Ph.D. Thesis, Technische Universität München, 2014.

[29] Roth, S., Hauder, M., Farwick, M., Matthes, F., Breu, R. Enterprise Architecture Documentation: Current Practices and Future Directions. In 11th International Conference on Wirtschaftsinformatik (WI'13) (Leipzig, Germany, February 27-March 01, 2013).

[30] Roth, S., Hauder, M., Matthes, F. Facilitating Conflict Resolution of Models for Automated Enterprise Architecture Documentation. In 19th Americas Conference on Information Systems (AMCIS '13) (Chicago, Illinois, USA, August 15-17).

[31] Roth, S., Hauder, M., Münch, D., Michel, F., Matthes, F. Facilitating Conflict Resolution of Models for Automated Enterprise Architecture Documentation. In: 19th Americas Conference on Information Systems (AMCIS '13), (Chicago, Illinois, USA, August 15-19, 2013).

[32] Shadbolt, N., Hall, W., Berners-Lee, T. The Semantic Web Revisited. IEEE Intelligent Systems, 21, 3: (May/June 2006), 96-101.

[33] Tamm T., Seddon, P.B., Shanks, G., Reynolds, P. How Does Enterprise Architecture Add Value to Organisations? Communications Of The Association For Information Systems, 28, 1 (2001), 141-68. 
[34] van der Raadt, B., Bonnet, M., Schouten, S., van Vliet, H. The relation between EA effectiveness and stakeholder satisfaction. The Journal of Systems and Software, 83, 10 (June 2010), 1954-1969.

[35] Walsham, G. Doing interpretive research. In European Journal of Information Systems, 15,3 (2006), 320-330.

[36] Webster, J., Watson, R.T. Analyzing the Past to Prepare for the Future: Writing a Literature Review, MIS Quarterly, 26, 2 (June, 2002), xiii-xxiii.

[37] Weill, P., Ross, J.W.: IT Savvy What Top Executives Must Know to Go from Pain to Gain. Harvard Business Press, 2009.

[38] Weiss, S., Aier, S., Winter, R. Institutionalization and the Effectiveness of Enterprise Architecture Management. In Proceedings of the International Conference on Information Systems (ICIS '13) (Milano, Italy, December 15-18, 2013).

[39] Wieland, K., Langer, P., Seidl, M., Wimmer, M., Kappel,, G. Turning Conflicts into Collaboration", Computer Supported Cooperative Work, Springer Verlag GmbH, 2012.

[40] Winter, R. Architectural Thinking. In Business \& Information Systems Engineering, 2014. 